\title{
The Greek Hybrid Version of the Assertive Community Treatment Model: A Perspective View between Challenges and Limitations
}

\author{
Vaios Peritogiannis* (D) and Fotini Tsoli \\ Mobile Mental Health Unit of the Prefectures of Ioannina and Thesprotia, Society for the Promotion of Mental \\ Health in Epirus, 54 Pashidi Str, 44445 Ioannina, Greece; ftsolh@yahoo.gr \\ * Correspondence: vaios.peritogiannis@medai.gr; Tel.: +30-26-5102-1227
}

Citation: Peritogiannis, V.; Tsoli, F. The Greek Hybrid Version of the Assertive Community Treatment Model: A Perspective View between Challenges and Limitations. Psych 2021, 3, 792-799. https://doi.org/ $10.3390 /$ psych 3040050

Academic Editor: Lucia Monacis

Received: 11 October 2021

Accepted: 1 December 2021

Published: 5 December 2021

Publisher's Note: MDPI stays neutral with regard to jurisdictional claims in published maps and institutional affiliations.

Copyright: (c) 2021 by the authors. Licensee MDPI, Basel, Switzerland. This article is an open access article distributed under the terms and conditions of the Creative Commons Attribution (CC BY) license (https:// creativecommons.org/licenses/by/ $4.0 /)$.

\begin{abstract}
The Assertive Community Treatment (ACT) model of care has been long considered to be effective in the management of patients with severe mental illness (SMI) in most Western countries. The implementation of the original ACT model may be particularly challenging in rural and remote communities with small and dispersed populations and lack of adequate mental health services. Rural programs may have to adapt the model and modify the ACT fidelity standards to accommodate these limitations, and this is the rationale for the introduction of more flexible, hybrid ACT models. In rural Greece, the so called Mobile Mental Health Units (MMHUs) are well-established community mental health services. For patients with SMI that have difficulties engaging with treatment services, the new hybrid ACT model has been recently launched. The objective of this manuscript is to present the recently launched hybrid ACT model in rural areas in Greece and to explore the challenges and limitations in its implementation from the experience of a team of mental health professionals with ACT experience. Referral criteria have not been strictly set, but the number of previous relapses and hospitalizations is taken under consideration, as well as the history of poor treatment adherence and disengagement from mental health services. The main limitation in the implementation of the hybrid ACT service is that it has been introduced in several areas in the absence of a pre-existing community mental health service. This may impact referrals and limit focus on the difficult cases of patients with SMI, thus making the evaluation of the model inapplicable.
\end{abstract}

Keywords: assertive community treatment; community mental health; mobile mental health units; rural areas; severe mental illness

\section{Introduction}

In contemporary health systems, mental health care is patient-oriented with a focus on recovery and is being delivered in less restrictive environments, that is, the community [1]. Accordingly, several generic and specialized community mental health services have been launched over the last decades, mostly in Western countries, with the aim to prevent and treat mental disorders in the community [2]. Those services prioritize patients with severe mental illness (SMI) and use interdisciplinary work to address the multifaceted needs of the patients [3].

Previous research has shown that generic community mental health teams may be effective in reducing hospitalizations and suicide rates, whereas their impact on patients' symptomatology and disability may be less profound [4]. Notably, a significant minority of approximately $30 \%$ of patients with SMI disengage from treatment with traditional services [5,6]. Accordingly, generic services evolved to specialized and highly specialized services, such as Assertive Community Treatment (ACT). ACT is a highly intensive, teamoperated, community-based service that provides treatment to individuals who have had difficulty engaging in traditional treatment services. The goals of ACT are individualized and include community integration and continuity of care across medical and psychiatric settings [7]. However, the implementation of such services in rural areas may be challeng- 
ing. The aim of the present paper is to present the recently launched hybrid ACT model in rural areas in Greece and to explore the challenges and limitations in its implementation.

\section{The Origins and Principles of the ACT Model}

The so-called ACT model originated from Stein and Test's experimental home-based treatment service in the United States in the early 1970s. It gradually evolved to what became known as ACT and is intended for patients with SMI who have difficulties engaging with services and are subjected to repeated hospitalizations [8,9]. ACT is a costly model of care which prioritizes patients with high levels of needs, such as patients with psychotic or severe affective disorders with multiple and potentially dangerous relapses, poor medication adherence, alcohol/substance abuse, maladaptive personality traits, and delinquent behavior [10]. It may not be intended for stable, severely disabled, isolated patients with schizophrenia with marked negative symptoms. Those patients may find increased level of contact with services distressing [11]. This model of care has expanded widely over the last few decades, mostly in highly resourced settings in Western countries, such as the U.K. and Australia.

The basic principles of the ACT model are in vivo assessment, training, and support. ACT uses assertive outreach to engage reluctant patients, whereas another core ingredient of the model is a holistic approach to services, including illness management, medication adherence, housing, and finances [9]. To achieve treatment goals, ACT uses multidisciplinary work and maintains a low client-staff ratio of approximately 10 clients per full-time ACT practitioner. Moreover, ACT teams provide continuous coverage and are committed to long-term care, and respond to patients' emergencies $24 \mathrm{~h}$ per day, 7 days per week [9].

\section{The Evidence for the ACT Model}

Many studies worldwide have assessed the effectiveness of the ACT model. The effectiveness of the ACT model of care in the United States has been supported by large studies and meta-analyses. In a national study of a large sample of Veterans Affairs patients with schizophrenia, ACT was associated with higher levels of antipsychotic adherence, and this effect was stable over time. Notably, the higher the level of ACT use, the higher the medication adherence [12]. A previous meta-analysis found that patients receiving ACT were more likely to remain in contact with services than those receiving standard community care. Those patients were less likely to be admitted to the hospital and spent less time in the hospital. In addition, patients receiving ACT had better outcomes on accommodation status and employment, and greater satisfaction among both patients and families was also recorded. There were no differences between ACT and control treatments on mental state or social functioning of patients [13]. Other modified ACT models have been studied, yielding positing effects for patients [14]. Moreover, ACT has been studied in special patient populations with SMI, such as the homeless [15] and the youth [16]. Generally, ACT was found to offer significant advantages over standard care models in reducing severity of psychiatric symptoms, improving general functioning, and reducing duration and frequency of psychiatric hospital admissions. Finally, ACT was found to be effective in under-resourced settings, such as in low- and middle-income countries [17].

Previous research has shown a link between fidelity (that is, the scope of the implementation of the essential features of a model) and the ACT model and its effectiveness. A meta-analysis assessed the relationship between ACT fidelity and reduction of hospital use. It was found that organization (e.g., $24 \mathrm{~h}$ access) predicted significant reductions in hospital use, while staffing (e.g., low client-staff ratio and optimal team size) did not [18].

\section{The Controversies over the ACT Model}

Despite the robust evidence on the effectiveness of the ACT model of care in the United States and the widespread implementation of this service, several concerns have emerged regarding its effectiveness in European countries. Indeed, some large-scale evaluations in the U.K. failed to show any advantage for ACT over standard services, such as community 
mental health teams (CMHTs), which already adopted many of the components of the ACT model [19]. It has been argued that ACT may have no advantage in terms of admissions reduction compared to similarly organized but lower cost CMHTs [20]. In the Netherlands, ACT was found to be more effective than treatment as usual in engaging patients to treatment, but no differences were detected with regard to admission days, functioning, patients' symptomatology, and quality of life [21]. These notions were further supported by the meta-analysis, which found no differences between ACT and control treatments on mental state or social functioning [13]. Accordingly, some scholars suggested that ACT may be effective only in communities with inadequate community mental health systems and an overutilization of psychiatric hospitals [20].

\section{The Case of Rural Areas}

Adults residing in rural geographic locations may receive mental health treatment less frequently, often with providers with less specialized training compared to those residing in metropolitan locations [22]. The reasons underlying this mental health treatment disparity include paucity of mental health services, reduced access and underutilization of available services, and professional staffing shortages [22]. The utilization of mental health services is affected by distance as well; the longer the distance, the less the service is used [23]. Moreover, mental health service accessibility is limited in socioeconomically deprived areas [24]. These notions may be particularly relevant in rural and remote areas, where residents face long travel times and other costs in accessing centrally located services. In addition, there may be considerable difficulties in recruitment and retention of specialized staff in those areas [25]. All these barriers are common in rural areas and undermine the delivery of mental healthcare.

\section{The Rationale for the Hybrid ACT Model}

According to Burns [10], there is little evidence that ACT should always conform to the originally proposed strict model, and adjustments to local variations are rational and justified. If these teams are integrated in a comprehensive local system of care, there is little need for $24 \mathrm{~h}$ coverage, and the staff-patient ratio may be more than 1:10. Indeed, in places with fully staffed and well-organized CMHTs, which adopt several of the core ingredients of ACT, the latter may be preserved for patients that do not engage in treatment with the CMHTs and have multiple relapses and hospitalizations.

The practice of adjusting the ACT model according to areas' needs and available resources seems to be widespread. Across the United States, less than $20 \%$ of facilities with ACT reported offering all core ACT services, and significant between-state variability was observed [26]. This practice is in line with recent suggestions that ACT implementation should evolve to meet new challenges that have emerged due to changes in the psychosocial context of individuals with SMI, clinicians' evolving competencies, and the ongoing reform of mental healthcare systems worldwide [27].

It has been argued that the implementation of the original ACT model may be particularly challenging in rural areas due to sparsely populated communities, the lack of adequate mental health services, and the difficulties in recruiting and retaining personnel $[9,28]$. Accordingly, rural programs may have to adapt the model to accommodate these barriers. Such adaptations may lead to wide variability, and to significant modifications to ACT fidelity standards. Other potential adjustments to the model, such as creating smaller ACT teams to accommodate small and dispersed populations, may be warranted [28]. Indeed, to address the needs of patients with SMI in rural settings, a hybrid service model called flexible ACT was launched in Denmark, providing intensive services for patients in crisis who are easily referred to usual services afterwards [29]. A subsequent evaluation of the program showed that there were statistically significant improvements in patients' compliance, unmet needs, and quality of life [30]. 
Mental healthcare delivery in rural Greece is still challenging due to socioeconomic factors and lack of adequate services. To address the rural areas' mental health needs, the Greek state has launched several interdisciplinary teams, the so-called Mobile Mental Health Units (MMHUs), over the last decades. These low-cost units deliver generic mental health care by using the infrastructures and resources of well-established primary healthcare systems in those areas [31-33]. Patients with SMI, who are mostly in need of a wide range of interventions, are prioritized by MMHUs in rural Greece. The range of interventions of the interdisciplinary MMHUs in rural Greece is broad and may help patients with chronic and severe mental disorders to live independently in the community. Through teamwork, those services address clinical symptomatology and can also help patients benefit from social services and encourage them to visit primary healthcare settings. Both are relevant in the care of those patients, given the disability that often accompanies psychotic disorders and the high rates of physical morbidity in those patients [34,35]. However, MMHUs may also treat common mental disorders because they may be the only available mental health services in those areas [36,37].

It has been previously shown that MMHUs effectively engage patients with chronic psychotic disorders for long-term treatment [38]. This probably accounts for the observed decrease in both voluntary and involuntary hospitalizations in those patients, as well as the decrease in hospital length of stay [39]. Moreover, a recent study suggested that such care may be cost-effective, as it can minimize public expenditures as well as patients' income and productivity losses by improving their mental health status [40].

\section{The Greek Hybrid Model of ACT}

Community mental health services in rural Greece, in the form of MMHUs, may be effective in the management of patients with SMI. However, some severely ill patients are particularly difficult to engage in treatment. To address this issue, the Greek state launched a hybrid model of ACT in 2018. This involved the expansion of the well-established MMHUs in rural areas, and the expansion of community mental health centers (CMHCs) and outpatient psychiatric departments of general hospitals in cities, respectively.

With regards to the workforce of the ACT teams, a separate team of four mental health professionals was added to the existing workforce of the aforementioned services. This team comprises the specialties of psychiatrists, psychologists, social workers, and nursing staff. There are no prerequisites for the hiring of new staff in terms of experience, training, or specific skills, although previous experience or training in community mental health is highly appreciated. Indeed, there is a lack of mental health professionals with an expertise in community mental health in Greece that could staff the ACT teams. Moreover, the new ACT teams cooperate closely with the pre-existing, well established community mental health services and their work is supervised by experienced clinicians. Accordingly, training and experience of their workforce may not be issues of concern.

The cost of the hybrid ACT model in Greece is rather low. The main reason is that several costly characteristics of the original ACT model, such as the $24 \mathrm{~h}$ operation and full staffing, are not involved in the present model. Moreover, the new hybrid ACT teams use the infrastructure of the pre-existing mental health services. They share the same offices and have common weekly team meetings. They also use the same electronic database. Other materials that are needed, such as computers or cell phones, are provided by the implementing institution. Indeed, those newly launched teams may use the least resources, as they work exclusively by carrying out domiciliary visits to patients. For their transportation, they use vehicles that are provided by their institution.

The Greek version of the ACT model prioritizes the most severe cases of patients with SMI. Although referral criteria have not been strictly set, the number of previous relapses and hospitalizations is always taken into consideration. Indeed, the most important criterion for the referral of a patient to the ACT team is the history of poor treatment adherence and disengagement from mental health services. This means that patients who are rated as difficult to engage in treatment with local mental health services are mostly 
referred to the new hybrid service. Accordingly, those teams should accept referrals only from established MMHUs, or from the inpatient and outpatient psychiatric wards of the area. Other referrals, such as primary care referrals or referrals from patients and families themselves, are managed in the context of community mental health services and may be referred to the ACT teams afterwards, when needed. This focus on patients that are difficult to engage in treatment was previously applied in Switzerland, although it only involved time-limited ACT, and aimed to facilitate linkage with outpatient care [41].

There are several challenges in the implementation of the hybrid ACT model in Greece. The most important is that such teams have been introduced in several areas in the absence of a pre-existing MMHU or CMHC. This may result in referrals of all mental disorders to those teams, including common mental disorders and organic brain disorders. This, in turn, may limit their focus on the difficult cases of patients with SMI that they are supposed to care for. Another important challenge in the implementation of this model in rural areas is distance. Due to the sparsity of the population in rural areas in Greece, those teams may have to travel long distances to visit patients at home. This may limit the number of engaged patients, due to time constraints, given the ACT teams' potential to only cover the $8 \mathrm{~h}$ morning shift.

With regards to the use of telepsychiatry by ACT teams, it has been previously described in the United States context as a means of expanding the reach of and access to $\mathrm{ACT}$, although the evidence on its effectiveness is limited. Moreover, there are concerns regarding information that may be missed with telepsychiatry [7]. The use of telepsychiatry has been employed by community mental health services in Greece as well, mostly in the islands [42]. However, telepsychiatry may not be regularly used by the Greek hybrid ACT, as an unknown but significant percentage of patients with SMI in rural Greece may not have access to the internet.

There may be differences among the Greek hybrid ACT model and other modifications of ACT across countries. The implementation of modified ACT in several European countries, such as Denmark, Sweden, and the Netherlands is based on the so-called flexibleACT (FACT). The FACT teams employ a flexible switching system that can adjust the intensity of treatment according to patients' needs, from case management to full intensive team care $[30,43,44]$. This is not the case for the hybrid ACT model in Greece, which has no potential of switching to full ACT care. Other differences include the strictly defined catchment area of 50,000 inhabitants in the FACT model and the staffing with specialties such as a peer specialist and supported employment specialist. In the case of the Greek hybrid ACT model, catchment areas are much larger, and the aforementioned specialties are lacking.

\section{Limitations in the Implementation of the Hybrid ACT Model in Greece}

A potential limitation of the implementation of the hybrid ACT model in Greece is the absence of pre-existing community mental health services and the lack of comprehensive local mental health networks. This could disrupt the focus on the most difficult cases of patients with SMI and would make the evaluation of the model inapplicable. To address this issue, the ACT teams should clarify their objective to all potential referral services, such as local primary healthcare and social services. Another limitation of the hybrid ACT model in Greece is the low fidelity to the standards of the originally proposed ACT. The newly launched teams are under-staffed, and services are delivered in an $8 \mathrm{~h}$ shift. A plausible way to address this issue is to increase the available resources and enrich the teams with other specialties. This would require a redesign of the program and it seems unlikely at present. Another limitation in the successful implementation of the hybrid ACT model in rural areas are the significant shortages of mental health professionals that are willing to work in those parts of the country [45]. To overcome these barriers, the Greek state should implement initiatives to recruit the required staff by providing financial incentives and support for professionals, such as training and professional development. Another potential limitation is the absence of clear criteria for the referral of a patient with 
SMI to these teams. On the other hand, this absence of referral criteria may add to the flexibility of the model.

Shortly after the introduction of this model to the community-based care system in Greece, the COVID-19 pandemic outbreak occurred. The referrals to the ACT teams reduced significantly, as well as their visits to the inpatient wards to meet patients that were hospitalized and would be referred afterwards. Moreover, some patients or their families were reluctant to accept domiciliary visits, due to safety concerns. However, with the ongoing vaccination of the patient population, these units now operate regularly, and their evaluation is yet to be performed. According to recent evidence, treatment performed by the established MMHUs in rural Greece may be cost-effective [40], but this has yet to be shown for the hybrid ACT model. Indeed, there is a dearth of research in Greece regarding the cost of SMI [46]. The Greek hybrid ACT model is not as costly as a high-fidelity ACT model, as its fidelity standards are rather low. Future research should address the issue of the cost-effectiveness of the model.

In a recent review of the scarce research on psychotic disorders in rural areas, the authors noticed that when patients with psychotic disorders in rural areas receive specialized mental health care, they have better outcomes than urban patients [47]. This may mean that the implementation of community mental health services in rural areas may lead to more positive outcomes. However, there are some concerns about the impact of the reduced size of the ACT team on patients' outcomes, which may differ from those with a fully staffed, high-fidelity team [28]. Whether this is the case of the hybrid ACT model in rural Greece remains to be tested by future research.

\section{Conclusions}

In conclusion, the hybrid ACT model of care in Greece aims to address the needs of patients with SMI that are difficult to engage in treatment with the already existing MMHUs and CMHCs. This form of hybrid treatment had to make several adjustments to adapt to the rural context by having small teams and low fidelity compared to the originally proposed model. Although MMHUs, which have adopted several of the core ingredients of ACT, may be cost-effective, it is yet to be shown for this hybrid model of care.

Author Contributions: All authors have made substantial contributions to the conseptualization, literature reviw and draft preparation of this article. All authors have read and agreed to the published version of the manuscript.

Funding: This research received no external funding.

Conflicts of Interest: The authors declare no conflict of interest.

\section{References}

1. Thornicroft, G.; Deb, T.; Henderson, C. Community mental health care worldwide: Current status and further developments. World Psychiatry 2016, 15, 276-286. [CrossRef]

2. Semrau, M.; Barley, E.A.; Law, A.; Thornicroft, G. Lessons learned in developing community mental health care in Europe. World Psychiatry 2011, 10, 217-225. [CrossRef]

3. Vita, A.; Barlati, S. The Implementation of Evidence-Based Psychiatric Rehabilitation: Challenges and Opportunities for Mental Health Services. Front. Psychiatry 2019, 10, 147. [CrossRef] [PubMed]

4. Simmonds, S.; Coid, J.; Joseph, P.; Marriott, S.; Tyrer, P. Community mental health team management in severe mental illness: A systematic review. Br. J. Psychiatry 2001, 178, 497-502. [CrossRef] [PubMed]

5. O'Brien, A.; Fahmy, R.; Singh, S.P. Disengagement from mental health services: A literature review. Soc. Psychiatry Psychiatr. Epidemiol. 2009, 44, 558-568. [CrossRef]

6. Doyle, R.; Turner, N.; Fanning, F.; Brennan, D.; Renwick, L.; Lawlor, E.; Clarke, M. First-Episode Psychosis and Disengagement From Treatment: A Systematic Review. Psychiatr. Serv. 2014, 65, 603-611. [CrossRef] [PubMed]

7. Swanson, C.L.; Trestman, R.L. Rural Assertive Community Treatment and Telepsychiatry. J. Psychiatr. Pract. 2018, 24, 269-273. [CrossRef]

8. Harvey, C.; Killaspy, H.; Martino, S.; Johnson, S. Implementation of Assertive Community Treatment in Australia: Model Fidelity, Patient Characteristics and Staff Experiences. Community Ment. Health J. 2011, 48, 652-661. [CrossRef]

9. Bond, G.R.; Drake, R.E. The critical ingredients of assertive community treatment. World Psychiatry 2015, 14, 240-242. [CrossRef] 
10. Burns, T. Planning and providing mental health services for a community. In New Oxford Textbook of Psychiatry, 2nd ed.; Gelder, M., Andreasen, N., Lopez-Ibor, J.J., Geddes, J., Eds.; Oxford University Press: New York, NY, USA, 2009; pp. $1452-1462$.

11. Burns, T. Community Mental Health Teams; Oxford University Press: New York, NY, USA, 2004.

12. Valenstein, M.; McCarthy, J.F.; Ganoczy, D.; Bowersox, N.W.; Dixon, L.B.; Miller, R.; Visnic, S.; Slade, E.P. Assertive Community Treatment in Veterans Affairs Settings: Impact on Adherence to Antipsychotic Medication. Psychiatr. Serv. 2013, 64, 445-451. [CrossRef] [PubMed]

13. Marshall, M.; Lockwood, A. WITHDRAWN: Assertive community treatment for people with severe mental disorders. Cochrane Database Syst. Rev. 2011, 4, CD001089.

14. Nordén, T.; Malm, U.; Norlander, T. Resource Group Assertive Community Treatment (RACT) as a Tool of Empowerment for Clients with Severe Mental Illness: A Meta-Analysis. Clin. Pract. Epidemiol. Ment. Health 2012, 8, 144-151. [CrossRef]

15. Coldwell, C.; Bender, W. The Effectiveness of Assertive Community Treatment for Homeless Populations with Severe Mental Illness: A Meta-Analysis. Am. J. Psychiatry 2007, 164, 393-399. [CrossRef]

16. Vijverberg, R.; Ferdinand, R.; Beekman, A.; van Meijel, B. The effect of youth assertive community treatment: A systematic PRISMA review. BMC Psychiatry 2017, 17, 284. [CrossRef]

17. Asher, L.; Patel, V.; De Silva, M. Community-based psychosocial interventions for people with schizophrenia in low and middle-income countries: Systematic review and meta-analysis. BMC Psychiatry 2017, 17, 355. [CrossRef]

18. Burns, T.; Catty, J.; Dash, M.; Roberts, C.; Lockwood, A.; Marshall, M. Use of intensive case management to reduce time in hospital in people with severe mental illness: Systematic review and meta-regression. BMJ 2007, 335, 336-340. [CrossRef] [PubMed]

19. Killaspy, H.; Kingett, S.; Bebbington, P.; Blizard, R.; Johnson, S.; Nolan, F.; Pilling, S.; King, M. Randomised evaluation of assertive community treatment: 3-year outcomes. Br. J. Psychiatry 2009, 195, 81-82. [CrossRef]

20. Burns, T. The rise and fall of assertive community treatment? Int. Rev. Psychiatry 2010, 22, 130-137. [CrossRef] [PubMed]

21. Sytema, S.; Wunderink, L.; Bloemers, W.; Roorda, L.; Wiersma, D. Assertive community treatment in the Netherlands: A randomized controlled trial. Acta Psychiatr. Scand. 2007, 116, 105-112. [CrossRef]

22. Morales, D.A.; Barksdale, C.L.; Beckel-Mitchener, A.C. A call to action to address rural mental health disparities. J. Clin. Transl. Sci. 2020, 4, 463-467. [CrossRef]

23. Zulian, G.; Donisi, V.; Secco, G.; Pertile, R.; Tansella, M.; Amaddeo, F. How are caseload and service utilisation of psychiatric services influenced by distance? A geographical approach to the study of community-based mental health services. Soc. Psychiatry Psychiatr. Epidemiol. 2011, 46, 881-891. [CrossRef]

24. Chiang, C.-L.; Chen, P.-C.; Huang, L.-Y.; Kuo, P.-H.; Tung, Y.-C.; Liu, C.-C.; Chen, W.J. Impact of universal health coverage on urban-rural inequity in psychiatric service utilisation for patients with first admission for psychosis: A 10-year nationwide population-based study in Taiwan. BMJ Open 2016, 6, e010802. [CrossRef]

25. Moore, T.; Sutton, K.; Maybery, D. Rural mental health workforce difficulties: A management perspective. Rural. Remote Health 2010, 10, 1519. [CrossRef]

26. Spivak, S.; Mojtabai, R.; Green, C.; Firth, T.; Sater, H.; Cullen, B. Distribution and Correlates of Assertive Community Treatment (ACT) and ACT-Like Programs: Results From the 2015 N-MHSS. Psychiatr. Serv. 2019, 70, 271-278. [CrossRef]

27. Thorning, H.; Dixon, L. Forty-five years later: The challenge of optimizing assertive community treatment. Curr. Opin. Psychiatry 2020, 33, 397-406. [CrossRef]

28. Meyer, P.; Morrissey, J. A Comparison of Assertive Community Treatment and Intensive Case Management for Patients in Rural Areas. Psychiatr. Serv. 2007, 58, 121-127. [CrossRef] [PubMed]

29. Van Veldhuizen, J.R. FACT: A Dutch version of ACT. Community Ment. Health J. 2007, 43, 421-433. [CrossRef]

30. Nugter, M.A.; Engelsbel, F.; Bähler, M.; Keet, R.; Van Veldhuizen, R. Outcomes of FLEXIBLE Assertive Community Treatment (FACT) Implementation: A Prospective Real Life Study. Community Ment. Health J. 2016, 52, 898-907. [CrossRef] [PubMed]

31. Peritogiannis, V.; Mavreas, V. Community mental health teams in Greece: The paradigm of Mobile Mental Health Units. Arch. Hell. Med. 2014, 31, 71-76.

32. Stylianidis, S.; Pantelidou, S.; Poulios, A.; Lavdas, M.; Lamnidis, N. Mobile Mental Health Units on the Islands: The Experience of Cyclades. In Social and Community Psychiatry; Stylianidis, S., Ed.; Springer: Berlin/Heidelberg, Germany, 2016 ; pp. 167-191.

33. Peritogiannis, V. Mental healthcare in rural Greece: An overview. Dialogues Clin. Neurosci. Ment. Health 2019, 2, 155-162.

34. Peritogiannis, V.; Manthopoulou, T.; Gogou, A.; Mavreas, V. Mental Healthcare Delivery in Rural Greece: A 10-year Account of a Mobile Mental Health Unit. J. Neurosci. Rural Pract. 2017, 8, 556-561. [CrossRef]

35. Peritogiannis, V.; Gioti, P. The scope of the interventions of an interdisciplinary mental health service in the treatment of psychotic disorders in rural Greece. Dialogues Clin. Neurosci. Ment. Health 2021, 4, 225-231.

36. Peritogiannis, V.; Mantas, C.; Alexiou, D.; Fotopoulou, V.; Mouka, V.; Hyphantis, T. The contribution of a mobile mental health unit in the promotion of primary mental health in rural areas in Greece: A two-year follow-up. Eur. Psychiatry 2011, 26, 425-427. [CrossRef] [PubMed]

37. Peritogiannis, V.; Rousoudi, S.; Vorvolakos, T.; Gioti, P.; Gogou, A.; Arre, A.; Samakouri, M. A comparative study of two Mobile Mental Health Units in different catchment rural areas in Greece. Int. J. Soc. Psychiatry 2021. online ahead of print. [CrossRef] [PubMed]

38. Peritogiannis, V.; Tatsioni, A.; Menti, N.; Grammeniati, A.; Fotopoulou, V.; Mavreas, V. Treatment Engagement of Psychotic Patients with a Mobile Mental Health Unit in Rural Areas in Greece: A Five-Year Study. Schizophr. Res. Treat. 2013, 2013, 61395. [CrossRef]

39. Peritogiannis, V.; Gioti, P.; Gogou, A.; Samakouri, M. Decrease of hospitalizations and length of hospital stay in patients with schizophrenia spectrum disorders treated in a community mental health service in rural Greece. Int. J. Soc. Psychiatry 2020, 66, 693-699. [CrossRef] [PubMed] 
40. Lykomitrou, A.; Geitona, M.; Stylianidis, S.; Pantelidou, S.; Souliotis, K. Economic Evaluation of Mobile Mental Health Units in Greece: The Case of Cyclades Islands. Health 2020, 12, 891-903. [CrossRef]

41. Bonsack, C.; Adam, L.; Haefliger, T.; Besson, J.; Conus, P. Difficult-to-Engage Patients: A Specific Target for Time-Limited Assertive Outreach in a Swiss Setting. Can. J. Psychiatry 2005, 50, 845-850. [CrossRef] [PubMed]

42. Garoni, D.; Sarantidis, D.; Katsadoros, K. Utilization of technological resources within the framework of operation of a Mobile Mental Health Unit. Psychiatry 2016, 27, 287-295. [CrossRef] [PubMed]

43. Svensson, B.; Hansson, L.; Lexén, A. Outcomes of clients in need of intensive team care in Flexible Assertive Community Treatment in Sweden. Nord. J. Psychiatry 2018, 72, 226-231. [CrossRef]

44. Nielsen, C.M.; Hjorthøj, C.; Killaspy, H.; Nordentoft, M. The effect of flexible assertive community treatment in Denmark: A quasi-experimental controlled study. Lancet Psychiatry 2021, 8, 27-35. [CrossRef]

45. Loukidou, E.; Mastroyiannakis, A.; Power, T.; Craig, T.; Thornicroft, G.; Bouras, N. Greek mental health reform: Views and perceptions of professionals and service users. Psychiatriki 2013, 24, 37-44. [PubMed]

46. Geitona, M.; Ollandezos, M.; Kousoulakou, C.; Agelopoulos, E.; Zaharakis, K.; Kakavas, P.; Karpouza, B.; Kesidou, S.; Bilanakis, N.; Papamichael, E.; et al. The cost of treating schizophrenia in Greece. Psychiatriki 2007, 18, 47-58. [PubMed]

47. Peritogiannis, V.; Samakouri, M. Research on psychotic disorders in rural areas: Recent advances and ongoing challenges. Int. J. Soc. Psychiatry 2021, 67, 1046-1057. [CrossRef] 